\title{
AN EXPERT SYSTEM FOR DATA ANALYSIS S/EXP AND ITS EFFECTIVENESS
}

\author{
Yuichi Ishibashi*, Keiko Takeda**
}

\begin{abstract}
Many kinds of statistical software are available, but most of them require the knowledge and experience of statistics. In such a circumstance a beginner of data analysis usually meets troubles when he starts an analysis without any advisors. We have developed an expert system for data analysis, we call it S/EXP. It is an expert system using $\mathrm{S}^{* * *}$. The system incorporates knowledge and experience of statistics. At present it contains only regression analysis among various possible procedures and the incorporated knowledge and experience are limited, but its effectiveness is recognized. We discuss the possibilities and problems of expert systems for data analysis.
\end{abstract}

\section{Purpose of the study}

A beginner of data analysis usually meets trouble in using a statistical package. The estimated reason is that he lacks knowledge and experience of data analysis, though usual packages assume such knowledge and experience. A beginner may manage to operate a statistical package and get some results but he is apt to make mistakes in interpreting them. This is the reason why we started in developing S/EXP.

Statistical packages we are using at this time do not support all process of actual data analysis. The followings are necessary for data analysis but are not supported by usual packages.

(1)A guide for statistical procedure corresponding to the purpose of data analysis.

(2)Methods to check the hypothetical conditions when applying a statistical procedures to the data.

(3)Methods to judge the appropriateness of a statistical procedure.

(4)Methods to evaluate the statistical results.

If a beginner studies the above points by himself, the following problems and many other difficulties may occur.

(1)A long time is necessary until he can understand the statistical literatures and the manuals of statistical packages.

(2)He needs to refer many literatures, as the necessary knowledge and experience are not collected in a single literature.

(3)It is difficult to build commands of package to analyze the data, because it is a kind of programming.

(4)Knowledge obtained by experience is not collected.

* NEC Corporation, Minato-ku, Tokyo 108, Japan.

** NEC Software Ltd., Minato-ku, Tokyo 108, Japan.

*** $S$ is a language which offers a programming environment for data analysis, and is developed by UNIX System Laboratories Inc.

Key words : Expert system; Data analysis; Regression analysis. 


\section{YUICHI ISHIBASHI and KEIKO TAKEDA}

(5)He can get some results by using a package even if they are meaningless because of a

mistake in applying statistical procedures.

At this time it is difficult to solve all of the above problems with software. Even if it is technically possible to make an automatic analysis system, we should leave a room for the user in judgement. The user should make final decisions by using the information given by the package. In designing this expert system, we have discussed when the system should give effective information and what kind of information it should give to the user to help him.

We have studied the possibilities to incorporate the knowledge and experience of data analysis in the system and how and when the system gives such information to the user. We have realized it as an actual system S/EXP.

\section{Incorporation of the process of data analysis}

We show the process of data analysis and the knowledge and experience necessary in such process. Also we discuss the possibilities to incorporate them in a system.

The process of data analysis and necessary knowledge are in Table 1.

Table 1. Process of data analysis and necessary knowledge

\begin{tabular}{|c|c|c|}
\hline Step & Detail & Necessary knowledge \& experience \\
\hline $\begin{array}{l}\text { 1. Make clear the } \\
\text { purpose of } \\
\text { analysis }\end{array}$ & $\begin{array}{l}\text { Study the causal relationship, } \\
\text { classify data, compose } \\
\text { variables, and so on, } \\
\text { then consider what kinds of } \\
\text { statistical procedure to apply. }\end{array}$ & $\begin{array}{l}\text { Knowledge of statistics and } \\
\text { experience to analyze data. }\end{array}$ \\
\hline 2.Examine data & $\begin{array}{l}\text { Inquire meaning of variables } \\
\text { and check whether the data } \\
\text { is appropriate to the purpose } \\
\text { of analysis. }\end{array}$ & $\begin{array}{l}\text { Background knowledge of } \\
\text { the data. }\end{array}$ \\
\hline $\begin{array}{l}\text { 3. Check scale of } \\
\text { each variable }\end{array}$ & $\begin{array}{l}\text { Distinguish variables between } \\
\text { continuous and discrete, and } \\
\text { produce some new variables } \\
\text { such as ratio or index. }\end{array}$ & $\begin{array}{l}\text { Knowledge of the meanings } \\
\text { of scale and new variables. }\end{array}$ \\
\hline $\begin{array}{l}\text { 4. Select a method } \\
\text { of analysis }\end{array}$ & $\begin{array}{l}\text { Decide statistical procedure } \\
\text { according to purpose and data } \\
\text { type. }\end{array}$ & $\begin{array}{l}\text { The meaning of statistical } \\
\text { procedure and the relationship } \\
\text { between data type and statistical } \\
\text { procedure. }\end{array}$ \\
\hline 5.Input data & $\begin{array}{l}\text { Input original data according } \\
\text { to data structure of } \\
\text { statistical package. }\end{array}$ & $\begin{array}{l}\text { Data structure of package and } \\
\text { method to manage missing values } \\
\text { in package. }\end{array}$ \\
\hline 6.Clean data & $\begin{array}{l}\text { Check whether data satisfy } \\
\text { statistical assumptions, and } \\
\text { eliminate problems after } \\
\text { checking using data } \\
\text { transformations etc. }\end{array}$ & $\begin{array}{l}\text { Knowledge how to check the } \\
\text { assumptions using graphs etc. }\end{array}$ \\
\hline $\begin{array}{l}\text { 7.Apply a method } \\
\text { of statistical } \\
\text { analysis }\end{array}$ & $\begin{array}{l}\text { Evaluate statistical results } \\
\text { and simplify statistical } \\
\text { model. }\end{array}$ & $\begin{array}{l}\text { Usually simplification of model } \\
\text { requires some experiences. }\end{array}$ \\
\hline $\begin{array}{l}\text { 8.Interpret the } \\
\text { obtained results }\end{array}$ & $\begin{array}{l}\text { In case of regression, residual } \\
\text { analysis is required. }\end{array}$ & $\begin{array}{l}\text { Knowledge of check of model } \\
\text { method to cope with ill } \\
\text { conditioned model. }\end{array}$ \\
\hline
\end{tabular}


An expert system for data analysis S/EXP and its effectiveness

We discuss the incorporation of the knowledge and experience in table 1 in a system. They are classified into two categories from the viewpoint of easiness of incorporation as shown in table 2 .

Table 2. Classification of knowledge and experience

\begin{tabular}{|c|c|c|}
\hline & Possible to incorporate & Difficult to incorporate \\
\hline Knowledge & $\begin{array}{l}\text { Knowledge given in statistical } \\
\text { literatures, but it is difficult } \\
\text { to decide when and in what level } \\
\text { to show the knowledge. } \\
\text { Steps } 3,4,5,6,7\end{array}$ & $\begin{array}{l}\text { Knowledge about data and } \\
\text { background of data. }\end{array}$ \\
\hline Experience & $\begin{array}{l}\text { Threshold of decision, for } \\
\text { example multiple correlation } \\
\text { coefficient. } \\
\text { Step } 7\end{array}$ & $\begin{array}{l}\text { Knowledge of background of data } \\
\text { and try and error in deciding a } \\
\text { model are required. } \\
\text { Steps } 1,8\end{array}$ \\
\hline
\end{tabular}

The knowledge and experience possible to incorporate in system may include decisions based on the values of statistics and advice to users expressed in simple sentences. The decisions are written in knowledge expressions such as IF THEN production rules. But all decisions should not be done automatically by the system. It is better that the system gives only cautions and information helpful for the user to decide. The reasons are that the decision usually has a relationship with knowledge difficult to incorporate and that it is dangerous to decide using only the knowledge easy to incorporate. From the above discussion it is appropriate for the system to indicate the following information.

(1)Results of decisions by the system.

(2)Information necessary for users to understand the results.

(3)Information necessary for users to conclude.

(4)Information necessary for users to decide in the case that the system can not make any decision.

\section{Goal of the system}

There are two types of knowledge and experience as discussed in the previous section. Among them we consider knowledge and experience possible to incorporate, and study the way how to show them to users. Our goal is to incorporate such knowledge and experience in our system to make the system useful for beginners. Hence, we define a beginner as a person who knows fundamental knowledge of statistics and enough knowledge of background and meaning of data. This expert system is just at a trial level, and the contained statistical procedure is only regression analysis. But, we suppose that the fundamental part of the decision to select statistical procedure is already established.

Table 3 shows the knowledge and experience incorporated in the system. The numbers correspond to the steps in table 1 . The results of the tests in table 3 are indicated at the level of warning or fatal. When the threshold value is not available, values in table 3 are set by our experience. 
YUICHI ISHIBASHI and KEIKO TAKEDA

Table 3. Knowledge and experience incorporated in the system

\begin{tabular}{|c|c|c|}
\hline & Steps of analysis & Realized functions in the system \\
\hline Knowledge & $\begin{array}{l}\text { 6.Clean data. } \\
\text { 7.Apply a method of } \\
\text { statistical analysis. }\end{array}$ & $\begin{array}{l}\text { Automatic tests on data: } \\
\text { if there are missing values or not, } \\
\text { if there is outlier or not, etc. } \\
\text { Automatic tests on results of analysis: } \\
\text { t-test, F-test, test on multiple } \\
\text { correlation coefficient. }\end{array}$ \\
\hline Experience & $\begin{array}{l}\text { 7. Apply statistical analysis. } \\
\text { 8.Interpret the obtained } \\
\text { results. }\end{array}$ & $\begin{array}{l}\text { Explanations on tests and how to cope } \\
\text { with when problems are found. } \\
\text { Check of the obtained model and data } \\
\text { using various techniques of regression } \\
\text { diagnostics: } \\
\text { normality test of residuals, abnormal } \\
\text { value test, independency in variables, } \\
\text { multiple correlation, linearity of } \\
\text { variables. }\end{array}$ \\
\hline
\end{tabular}

\section{Development of the system}

The system S/EXP has been developed on NEC's engineering work station EWS4800 using $\mathrm{S}$. The reasons are as follows:

(1)A multiple window system is necessary, because many kinds of information are displayed at a time, and a high resolution display and high performance are needed as hardware.

(2)As a functional language is available in $S$, the rules of automatic tests and new functions can be described easily.

In addition to the rules and functions written in $S$, the controller of the system and the window interface are programmed using $\mathrm{C}$ language.

We designed the system considering the following points in order to make the system easy to use.

(1)Users can see parameters, numerical results and related graphs at a time through multi windows.

(2)All statistical tests are performed at a time and the results are displayed in a summarized form like a check list for the convenience to find problems easily.

(3)Rule description is written in S's language, and the execution is performed under S.

(4)Models are expressed using data structure of S. Some functions are added to save and compare the obtained models so that the user can choose the most appropriate model.

The figure 1 shows the display which contains many kinds of information using a multi window system. Each window is explained below.

Upper left:Results of regression analysis. Estimated regression coefficients, $t$-value, significant level of t-test and multiple correlation coefficient adjusted by degrees of freedom.

Middle left:Instruction window. System demands user to select the test.

Lower left:Window to input parameters for regression analysis, such as dependent and independent variables, regression model name.

Lower middle:List of variable names.

Upper right:Histogram for a variable.

Middle right:Explanations on dependent variable and guide for manner to in parameter input window.

Lower right:Check list for results of analysis. Test level and test result about effectiveness of independent variables and significance of fitness of model. 
The detail of automatic tests is as follows. The rules of automatic tests are classified according to the category of test, such as data check, residual analysis, and so on. Each check list displays the following items.

Results of test and knowledge to interpret.

Knowledge of method of tests.

Knowledge of method to cope with problems.

The summary of results of tests in a check list is displayed in different colors according to the level of problem. The rules are described in the following expressions. The example is the rule of test for the result of regression analysis.

(IF:t-value of variable $<5 \%$ significant point of $t$-distribution)

(THEN:effectiveness of variable has problem)

(IF:F-value of model $<5 \%$ significant point of F-distribution)

(THEN:significance of model has problem)

(IF:multiple correlation coefficient $<0.6$ )

(THEN:fitness of model has problem)

The threshold 0.6 in the last rule is set by experience. This value can be changed by user.

An example of check list is shown in figure 2. Check list contains three kinds of information.

The example is one of them, results of test and knowledge to interpret them.

Test item:effectiveness of independent variable.

Test level:warning.

Result of test:failed.

Explanation:the following independent variable is not significant.

Variable names, $\mathrm{t}$-values, probabilities of $\mathrm{t}$-values are displayed.

General knowledge:Regression analysis estimates a regression model in which a dependent variable is expressed by some independent variables with linear expression. The degree of influence of independent variables on dependent variable is known according to the absolute value of estimated regression coefficients.

Test for each regression coefficient is performed by $t$-test and the hypothesis is that regression coefficient is 0 .

The probability of $t$-test is probability of occurrence of hypothesis. If the probability is small, the hypothesis that regression coefficient is 0 is rejected.

\section{Evaluation of the system}

The system was used by some people experimentally. It is an convenient system as a whole. Needless to say, each evaluation varies depending on the personal experience in statistical software. We examine it in detail.

The check list of automatic tests is very effective in analysis. The advantages of the check list are as follows:

(1)Looking the whole results of tests at a time the user find problems easily without constructing commands.

(2)By examining possible methods by try and error, the user can choose the most appropriate method to solve the problems.

(3)Usually a beginner only fit a regression model to the data, but using this system he concentrates on solving the problems in the model and data.

As a user receiving different kinds of information such as numerical results along with the related explanation, at a time with a multi window system, he can understand results and problems easily.

Finally, it is expected that using this system a beginner level of analysis improves. And as expected it is proved that after using this system they can understand the meanings of higher 
level of techniques such as regression diagnostics to a certain extent.

There are some points to improve this system. The process of data analysis contains many steps, from the check of data to the evaluation of results. A user may lose what he is doing and where he is in the process. To indicate the step in process, the system should give the information on what has been done up to this step and what will be done at next step. Block diagram may help him to understand the step where he is. There are many windows in a display, therefore the user interface may be a little bit complicated. To improve it, it is necessary to design windows imaging the manuals, notebooks and so on. In such window the user can recognize the function of each window easily. Suppose that the user works on the desk and that there are manuals, notebooks, list of variables, lists of results of regression analysis, literatures etc. on his desk. It is desired that each material corresponds to a window and each window images a goods on the desk. These problems may be solved with the present technique of computer. We are making effort to improve the system.

As a related work there is an expert system called REX(Regression EXpert) discussed in Gale(1986). It guides the analysis process by testing assumptions of regression, suggesting possible transformations when assumptions are violated, and justifying its suggestions when requested. REX's aims are quite similar to the present S/EXP's ones, but there are some differences between two systems.

The major differences are that S/EXP expects a beginner's usage, and that it provides a check list for statistical tests and statistical knowledge in a hierarchical structure in order for him to understand easily. We wish to develop a system which covers as many statistical procedures as possible. In the sense the present system is at an intermediate point of development. After incorporating other statistical procedures, we plan to expand the functions and knowledge of the system.

\section{Discussion}

This system has only regression analysis. An important point is to support the user for selecting a statistical procedure according to the purpose of analysis and the property of data. But it is not enough only to display information and to process statistical results with some rules. Knowledge of background and knowledge of data analysis should be synthesized. This could be obtained by experience of analyzing actual data. If the system prepares the circumstance where the user can analyze some actual data, he can acquire the experience without difficulties. Such a system is a kind of knowledge based CAI(computer assisted instruction), and it contains general knowledge and experienced knowledge of data analysis and background of data. We are studying such a system and developing a practical expert system for data analysis refining the present system.

\section{REFERENCES}

Becker,R.A.(1984).S An Interactive Environment for Data Analysis and Graphics, Wadsworth. Chatterjee,S. and Price,B.(1977).Regression Analysis by Example, John Wiley \& Sons.

Gale,W.A.(1986).Artificial Intelligence \& Statistics, Addison Wesley.

Sawa,T.(1979).Regression Analysis, Asakura Shoten.

Takeda,K. and Ishibashi,Y.(1987).Requirements for Data Analysis Systems, Proceedings of the 1st symposium of the Japanese Society of Computational Statistics.

Takeda,K.(1990).Possibilities and trial development of an expert system for data analysis,

Proceedings of 4th Conference of the Japanese Society of Computational Statistics.

Tanaka,Y.,Tarumi,T. and Wakimoto,K.(1984).Handbook of Statistical Analysis with Programs for Personal Computers, Vol.2 Multivariate Analysis, Kyoritsu Shuppan. 
Figure 1. Input parameters and results of analysis

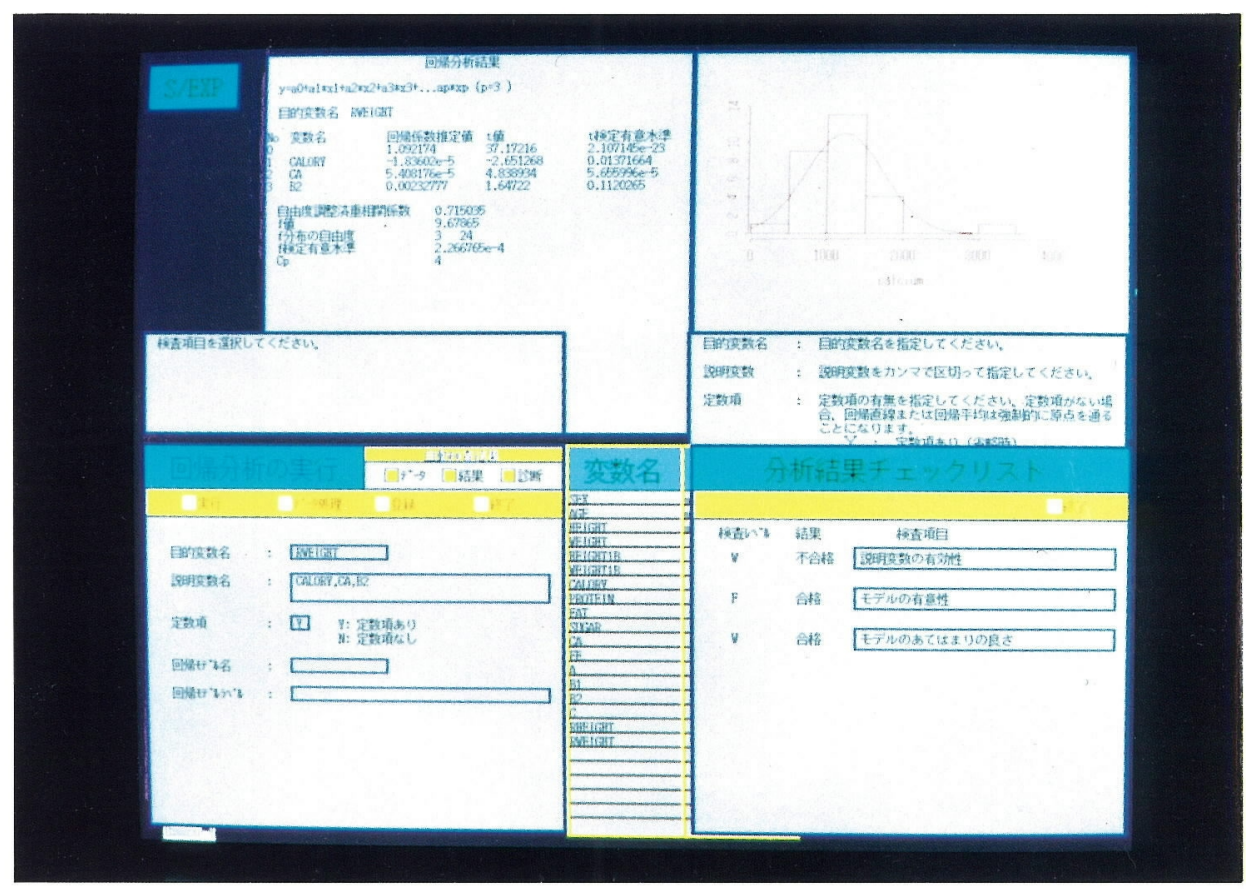

Figure 2. An example of check list

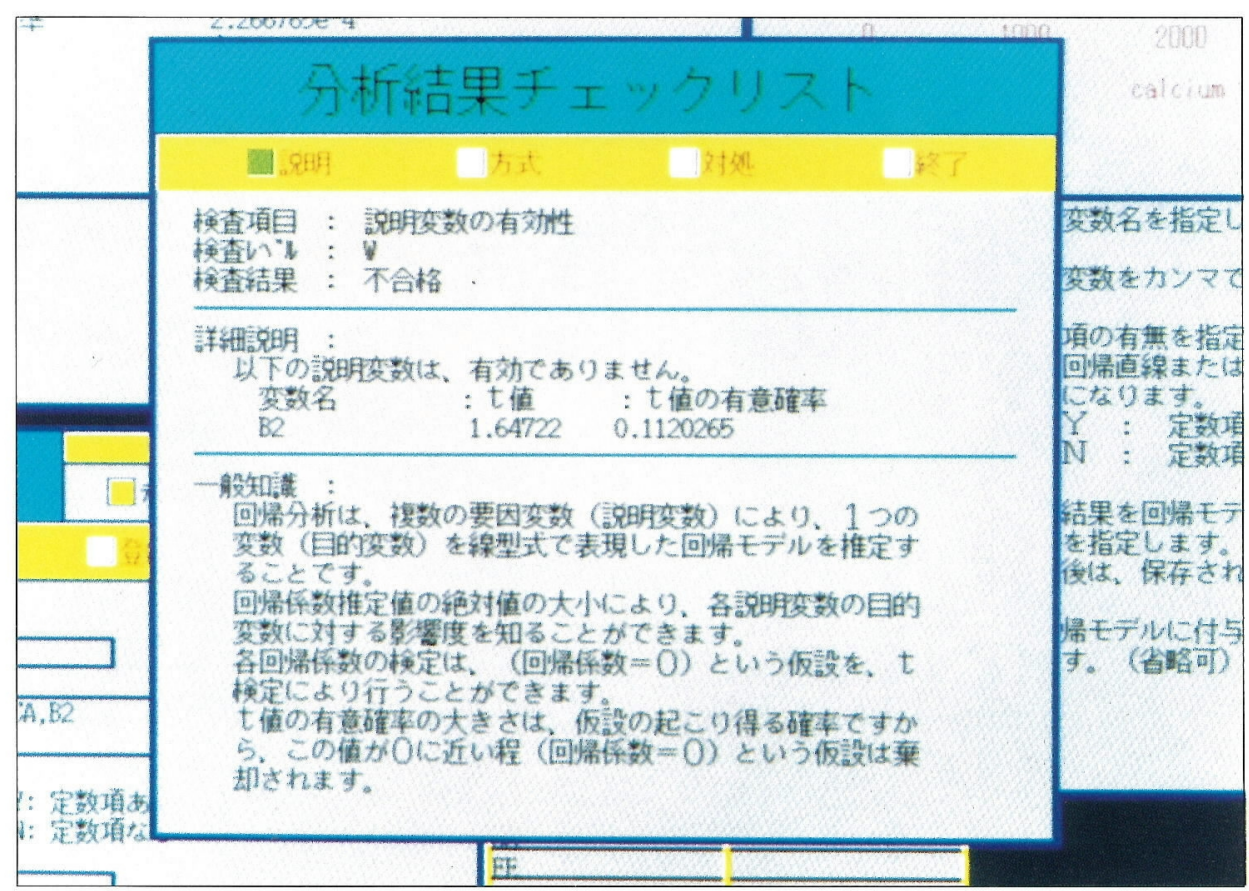

